\title{
ESTRATÉGIAS DE GESTÃO NO DESTINO DO LIXO TECNOLÓGICO: UM CASO DE IMPLANTAÇÃO DE UM ECOPONTO NA UNIGRANRIO
}

\author{
Daniel Teotônio Santos ${ }^{1}$ - dantteos@hotmail.com
}

Glória Maria Dias ${ }^{1}$ - gloriamaria1 @ ibest.com.br

Rubens Paulo de Almeida Santos 1 - rubenspauloo@gmail.com

Uellington Bruno da Silva ${ }^{1}$ - uellingtonbs@ bol.com.br

Vilson Vieira de Paula ${ }^{1}$ - vilson.adm@ bol.com.br

${ }^{1}$ UNIGRANRIO - Escola de Ciências Sociais Aplicadas

\section{RESUMO}

O acelerado avanço tecnológico tem causado a obsolescência dos equipamentos eletrônicos num curto espaço de tempo. Isso é o resultado do descarte de aparelhos eletrônicos, como computadores pessoais e celulares, entre outros, o lixo tecnológico é um problema cada vez mais aparente na sociedade atual. Quando não descartado adequadamente, o lixo tecnológico pode causar sérios danos à saúde e ao meio ambiente. A discussão sobre o lixo tecnológico nesta pesquisa, surgiu a partir do interesse de desenvolver um trabalho que envolvesse a Logística Reversa, buscando refletir sobre os impactos da tecnologia na sociedade. Nesse contexto, um dos objetivos é promover o uso ético e com responsabilidade social e ambiental das tecnologias. Esse artigo descreve os resultados de um estudo realizado sobre o lixo tecnológico, acerca de suas características, danos, riscos e legislação relacionada. O trabalho também trata da implantação de um Ecoponto dentro de um Campus Universitário. Ainda, apresenta-se levantamento acerca de locais para o descarte responsável. Com base nos dados obtidos, são definidas ações para o destino e reuso do lixo tecnológico, de forma a promover a sua gestão adequada.

Palavras-chaves: Tecnologia, Lixo Tecnológico, Logística Reversa e Reciclagem.

\begin{abstract}
The rapid technological advancement has caused the obsolescence of electronic equipment in a short time. This is the result of the disposal of electronic equipment such as personal computers and mobile phones, among others, the technological waste is an increasingly apparent problem in society today. When not disposed of properly, the e-waste can cause serious damage to health and the environment. The discussion of technological waste this research arose from the interest of developing a job involving the Reverse Logistics, trying to reflect on the impact of technology on society. In this context, one of the goals is to promote the ethical use and social and environmental responsibility technologies. This article describes the results of a study on e-waste, about their characteristics, damages, liabilities and related legislation. The work also deals with the establishment of a Ecoponto within a University Campus. Still, presents survey about places for responsible disposal. Based on the data obtained, actions to fate and reuse of e-waste, in order to promote their proper management are defined.
\end{abstract}

Keywords: Technology, Technological Waste, Recycling and Reverse Logistics. 


\section{INTRODUÇÃO}

A compra facilitada de equipamentos eletrônicos, como computadores e aparelhos celulares, entre outros, nos últimos anos, tem sido uma prática frequente entre os consumidores de todo o mundo. Desta forma, o mundo tenta entender muitas questões sobre o lixo tecnológico, como descartá-lo e de quem seria a responsabilidade pela gestão desses resíduos.

O lixo tecnológico recebe diferentes nomes: resíduo eletrônico, lixo eletrônico, e-waste, ou simplesmente e-lixo, sendo apenas diferentes no nome, mas configura o mesmo problema: são produtos eletrônicos sem utilidade. São, por exemplo, computadores, celulares, equipamentos de informática em geral, etc.

O problema do lixo tecnológico preocupa muito a sustentabilidade da vida no planeta, pois causa sérios danos ambientais, sendo considerado um problema de saúde pública.

Os avanços tecnológicos faz com que os equipamentos eletrônicos aumentem rapidamente, tornando-os, rapidamente, ultrapassados e ineficientes. Este rápido desuso dos eletrônicos e o aumento da produção e do consumo desses equipamentos, ajuda no crescimento do lixo tecnológico, e como consequência o problema se agrava a cada dia, deixando o planeta sem espaço para armazenamento e com pouca capacidade de reciclagem.

A utilização da Logística Reversa ajudará na investigação de como é feito a descartabilidade do lixo tecnológico e quais os produtos que podem ser produzidos através da reciclagem do mesmo, que para muitos ainda é desconhecido e neste trabalho, será desenvolvido um estudo de caso na Universidade Unigranrio em seu campus de Magé no Rio de Janeiro.

A implantação de Ecopontos em empresas e universidades representam ações necessárias, pois conscientiza a população, chamando a atenção para o destino correto do lixo tecnológico, tendo uma solução através da reciclagem. Assim, um maior esforço neste sentido é fundamental.

O lixo tecnológico é um problema de responsabilidade das empresas, dos consumidores e governos. Tanto as empresas quanto os governos não querem assumir a total responsabilidade quanto ao ciclo de vida dos equipamentos tecnológicos e, por sua vez, os consumidores não têm as informações necessárias quanto aos males do descarte indevido e também são desprovidos de alternativas para descartar equipamentos em desuso. Portanto, quais estratégias de gestão podem ser utilizadas no destino do lixo tecnológico?

O objetivo deste artigo é levantar o problema do lixo tecnológico, sua importância, impacto ambiental, consequências, situação nacional e mundial, ações e projetos preventivos e atuação das legislações, visando encontrar uma tentativa de formular estratégias de gestão e descarte do lixo tecnológico.

\section{O LIXO TECNOLÓGICO}

Para Schneider (2004, p. 20), este tipo de lixo apresenta caráter antropogênico, pois são únicos e exclusivamente gerados pelo homem em suas atividades diárias em sociedade, além disso, apresentam caráter inesgotável, uma vez que também é ilimitada a capacidade do ser humano de crescer numericamente ou em conhecimento e inventividade, gerando a cada dia novos produtos, promovendo sempre novas transformações nas matérias-primas.

O crescimento da produção de equipamentos eletrônicos é algo inevitável que logo em alguns anos o que é produzido hoje estará obsoleto num futuro bem próximo. A grande preocupação é o que fazer com a sucata gerada dia a dia e como produzir equipamentos que tenham em seus componentes, substâncias não tóxicas e recicláveis. 
Nesse contexto, surgem leis - federais e estaduais - que obrigam pessoas físicas e jurídicas a cuidarem do lixo tecnológico que produzem. Algumas empresas têm se antecipado e estão criando programas para recolher os produtos que produzem e que logo caem na inutilidade, reciclando-os ou dando uma disposição final correta.

A reciclagem consiste em transformar os materiais inúteis em novos produtos ou matérias-primas de forma a diminuir a quantidade de resíduos, poupar energia e recursos naturais valiosos, além de trazer os seguintes benefícios, como mostra o quadro 1:

Quadro 1 - Benefícios da Reciclagem

\begin{tabular}{|l|l|}
\hline \multicolumn{2}{|c|}{ Benefícios da Reciclagem } \\
\hline Desintoxicação & Contribui para diminuir a poluição do solo, água e ar. \\
\hline Despoluição & Melhora a limpeza da cidade e a qualidade de vida da população. \\
\hline Perenidade & Prolonga a vida útil de aterros sanitários. \\
\hline Compostagem & Melhora a produção de compostos orgânicos. \\
\hline Empregabilidade & Gera empregos para a população não qualificada. \\
\hline Econômico & Gera receitas com a comercialização dos recicláveis. \\
\hline Custo Energético & $\begin{array}{l}\text { Estimula a concorrência uma vez que os produtos gerados a partir dos reciclados são } \\
\text { comercializados em paralelo àqueles gerados a partir de matérias primas virgens. }\end{array}$ \\
\hline Imagem & Contribui para a valorização da limpeza pública e para formar uma consciência ecológica. \\
\hline
\end{tabular}

Fonte: Próprio autor, 2014.

\subsection{ASPECTOS LEGAIS}

Há legislações no Brasil que tratam exclusivamente do lixo tecnológico. As leis existem, desde federais (Lei Federal $n^{\circ} 12.305$ ) a estaduais, pois cada estado brasileiro carece de leis específicas para a questão do lixo tecnológico. Cada estado desenvolve seus princípios e objetivos de acordo com a cultura e costumes de seus habitantes. No entanto, todos alertam para a responsabilidade dos fabricantes, importadores, distribuidores e comerciantes, a estruturação e implementação de sistemas de Logística Reversa.

A Lei de Política Nacional de Resíduos Sólidos dispõe sobre os princípios, objetivos e instrumentos, bem como sobre as diretrizes relativas à gestão integrada e ao gerenciamento de resíduos sólidos, incluindo os perigosos, às responsabilidades dos geradores e do poder público e aos instrumentos econômicos aplicáveis.

Estão sujeitas à observância desta Lei as pessoas físicas ou jurídicas, de direito público ou privado, responsáveis, direta ou indiretamente, pela geração de resíduos sólidos e as que desenvolvam ações relacionadas à gestão integrada ou ao gerenciamento de resíduos sólidos, somente não sendo aplicada esta Lei aos rejeitos radioativos, que são regulados por legislação específica. Leia a citação a seguir:

Art. 33. São obrigados a estruturar e implementar sistemas de logística reversa, mediante retorno dos produtos após o uso pelo consumidor, de forma independente do serviço público de limpeza urbana e de manejo dos resíduos sólidos, os fabricantes, importadores, distribuidores e comerciantes de: agrotóxicos, seus resíduos e embalagens, pilhas e baterias, pneus, óleos lubrificantes, seus resíduos e embalagens, lâmpadas fluorescentes, de vapor de sódio e mercúrio e de luz mista e produtos eletroeletrônicos e seus componentes ${ }^{1}$.

\footnotetext{
${ }^{1}$ Lei Federal 12.305/2010 - Artigo 33, incisos I, II, III, IV, V, VI.
} 
A Política Nacional de Resíduos Sólidos reúne o conjunto de princípios, objetivos, instrumentos, diretrizes, metas e ações adotadas pelo Governo Federal, isoladamente ou em regime de cooperação com Estados, Distrito Federal, Municípios ou particulares, com vistas à gestão integrada e ao gerenciamento ambientalmente adequado dos resíduos sólidos.

\section{PROCESSO DE TRATAMENTO}

Para Franke (2004), a tradição da remanufatura, que era ajustada aos investimentos de longa duração como no caso de máquinas operatrizes, aviões, equipamentos militares e motores de automóveis, também foi estendido para um grande número de bens de consumo com o tempo de vida útil inferior e valores relativamente baixos. Celulares, rádios e computadores pessoais seriam exemplos desses novos produtos que são reprocessados. Uma alternativa à reciclagem convencional é a remanufatura, pois constitui na missão de atender as taxas de recuperação de produto e os tratamentos especiais na legislação.

O conceito de logística reversa preocupa-se com outros termos tal como a reciclagem e disposição dos resíduos, ele então destaca que a logística reversa é uma perspectiva da logística de negócios. O termo refere-se ao papel da logística no retorno de produtos, redução na fonte, reciclagem, substituição e reuso de materiais, disposição de resíduos, reformas, reparação e remanufatura, LEITE (2003).

A logística Reversa tem o papel de instrumento de desenvolvimento econômico e social, caracterizada por um conjunto de ações, procedimentos e meios, destinados a facilitar a coleta e a restituição dos resíduos sólidos aos seus geradores para que sejam tratados ou reaproveitados em novos produtos, na forma de novos insumos, em seu ciclo ou em outros ciclos produtivos, visando a não geração de rejeitos. (BRASIL, Projeto de Lei n ${ }^{\circ} 1991,2007$, art. $7^{\circ}$ inciso XII, p.3).

Na percepção da $\mathrm{ONU}^{2}$ (2002), governantes do mundo inteiro devem adotar medidas para incentivar a reciclagem de computadores e celulares obsoletos e o prolongamento de sua vida útil, devido ao impacto destrutivo dos componentes dessas máquinas para o meio ambiente. Destaca-se também que a fabricação de um computador de $24 \mathrm{Kg}$ exige 10 vezes mais o seu peso em combustível fóssil e mais produtos químicos. A fabricação de um computador e seu monitor requer aproximadamente $240 \mathrm{Kg}$ de combustível e $22 \mathrm{Kg}$ de produtos químicos.

A legislação e os sistemas direcionados para o tratamento de Equipamentos Eletro Eletrônicos (EEE) ${ }^{3}$, são implementados nos estados brasileiros trabalhos que devem proporcionar os pré-requisitos de um tratamento adequado, ajudando a indústria, além de analisar as potências de reciclagem, reuso e remanufatura de diferentes classes de produtos para o desenvolvimento sócio-econômico.

\subsection{IMPACTOS DO E-LIXO NO MEIO AMBIENTE E NO SER HUMANO}

O lixo tecnológico que é descartado em lugares impróprios, como aterros sanitários ou lixões ao céu aberto, constituem sérios riscos para o meio ambiente e saúde humana, pois possuem em suas composições diversas substâncias e elementos químicos extremamente nocivos à saúde, como metais pesados altamente tóxicos: mercúrio, chumbo, cádmio, etc. Esses metais em contato com o solo contaminam o lençol freático, chegando à água e consequentemente aos

\footnotetext{
${ }^{2}$ Pesquisa contratada pela ONU - Organizações das Nações Unidas, 2002.

${ }^{3}$ EEE - Equipamentos Eletro Eletrônicos
} 
homens por meio da alimentação. Se queimados, poluem o ar, e também contaminam pelo contato direto, causando doenças graves.

O lixo é disposto de qualquer maneira e sem nenhum tratamento, o que acaba causando problemas ambientais. Os equipamentos rejeitados são, na maioria dos casos, reduzidos à condição de lixo tecnológico e têm como destino o lixo comum, chegando aos aterros sanitários ou lixões. Aproximadamente 50 milhões de toneladas de lixo tecnológico são gerados todo ano no mundo, representando $5 \%$ de todo o lixo gerado pela humanidade.

As consequências para os seres humanos, animais e ambiente são graves, pois esses equipamentos possuem diversas substâncias e elementos químicos extremamente nocivos à saúde, principalmente os metais pesados. As pessoas podem se contaminar pelo contato direto, no caso de manipulação direta de placas eletrônicas e outros componentes perigosos dos eletroeletrônicos nos lixões a céu aberto.

A contaminação pode também ocorrer indiretamente ou de forma acidental, pois quando um eletrônico é jogado em lixo comum e vai para um aterro sanitário, há grande possibilidade de que os componentes tóxicos contaminem o solo chegando até o lençol freático, afetando também a água. Se essa água for usada para irrigação ou para dessedentar o gado, os elementos chegarão ao homem através da alimentação.

Medidas estão sendo tomadas e os fabricantes, cada vez mais, estão sendo pressionados a eliminar ou diminuir a quantidade de componentes tóxicos na fabricação dos produtos, entretanto, a produção de equipamentos inofensivos ao meio ambiente ou facilmente recicláveis ainda é um grande esforço para que aconteça. Além disso, os equipamentos obsoletos continuam chegando, em ritmo acelerado e sem controle, aos lixões.

\subsubsection{O Perigo dos Componentes Tóxicos de Computadores e Celulares}

Os metais pesados contidos nas baterias de celulares e em computadores, quando absorvidos, são de difícil eliminação pelo organismo, podendo causar diversos efeitos nocivos ao ser humano. Observe tais informações no quadro 2, a seguir.

Quadro 2: Efeitos do Cádmio, Mercúrio e Chumbo

\section{EFEITOS DO CÁDMIO, MERCÚRIO E CHUMBO}

O cádmio é um dos metais mais tóxicos. A principal via de absorção é a inalação em meios industriais ricos em fumos e poeiras de cádmio. Uma simples exposição a elevadas concentrações de óxido de cádmio pode causar graves irritações pulmonares ou mesmo a morte.

O mercúrio, à medida que ele passa ao sangue, liga-se as proteínas do plasma e nos eritrócitos distribuindo-se pelos tecidos concentrando-se nos rins, fígado e sangue, medula óssea, parede intestinal, parte superior dos aparelhos respiratório, mucosa bucal, glândulas salivares, cérebro, ossos e pulmões. É um tóxico celular geral, provocando desintegração de tecidos.

O chumbo é um metal pesado extremamente tóxico e que chega até os seres humanos principalmente pelo ar, água e cadeia alimentar, de forma acumulativa. Os seus efeitos tóxicos, entre outros, incluem sintomas como náusea, perda da coordenação, hiperatividade, confusão mental e perda de memória. Em casos mais severos, a incorporação deste elemento químico pode levar a pessoa ao estado de coma e à morte.

Fonte: MANIFESTZINE, 2010

As baterias dos celulares são hoje um problema ambiental. Contendo resíduos perigosos e compostas de metais pesados altamente tóxicos e não-biodegradáveis, como cádmio, chumbo e 
mercúrio, depois de utilizadas, a maioria é jogada em lixos comuns e vai para aterros sanitários ou lixões a céu aberto.

A forma como são eliminados e o consequente vazamento de seus componentes tóxicos contaminam o solo, os cursos d'água e o lençol freático, atingindo a flora e a fauna das regiões circunvizinhas. Através da cadeia alimentar essas substâncias chegam de forma acumulada aos seres humanos. Conforme apresentado no quadro 2.

\section{ESTRATÉGIAS DE GESTÃO NO DESTINO DO LIXO TECNOLÓGICO}

Um estudo sobre estratégias de gestão do lixo tecnológico é apresentado por Arantes (1994), onde é mostrada a estratégia de gestão como um conjunto de conceitos e técnicas que auxiliam a administração a definir os procedimentos e os métodos para execução das atividades, a fixar e compartilhar os papéis e as responsabilidades entre a equipe, a promover as relações e o entendimento comum. Ele define claramente a diferença entre Administração e Estratégia de Gestão, e a situar este como um elemento útil e necessário para que a Administração execute sua tarefa empresarial.

A Estratégia de Gestão é um conjunto de ferramentas que auxiliam o sistema a executar seus procedimentos de forma eficiente e eficaz (CHIAVENATO, 2000). As estratégias de gestão propostas neste trabalho se estrutura num conjunto de procedimentos compondo etapas estruturadas, objetivando o tratamento adequado de lixo tecnológico, de modo a evitar impacto no meio ambiente, preservando o ser humano e a disponibilidade de recursos naturais.

O fluxograma a seguir, traz estratégias de tratamento do lixo tecnológico na figura 1:

Figura 1: Fluxograma Estratégia de Gestão do destino do Lixo Tecnológico

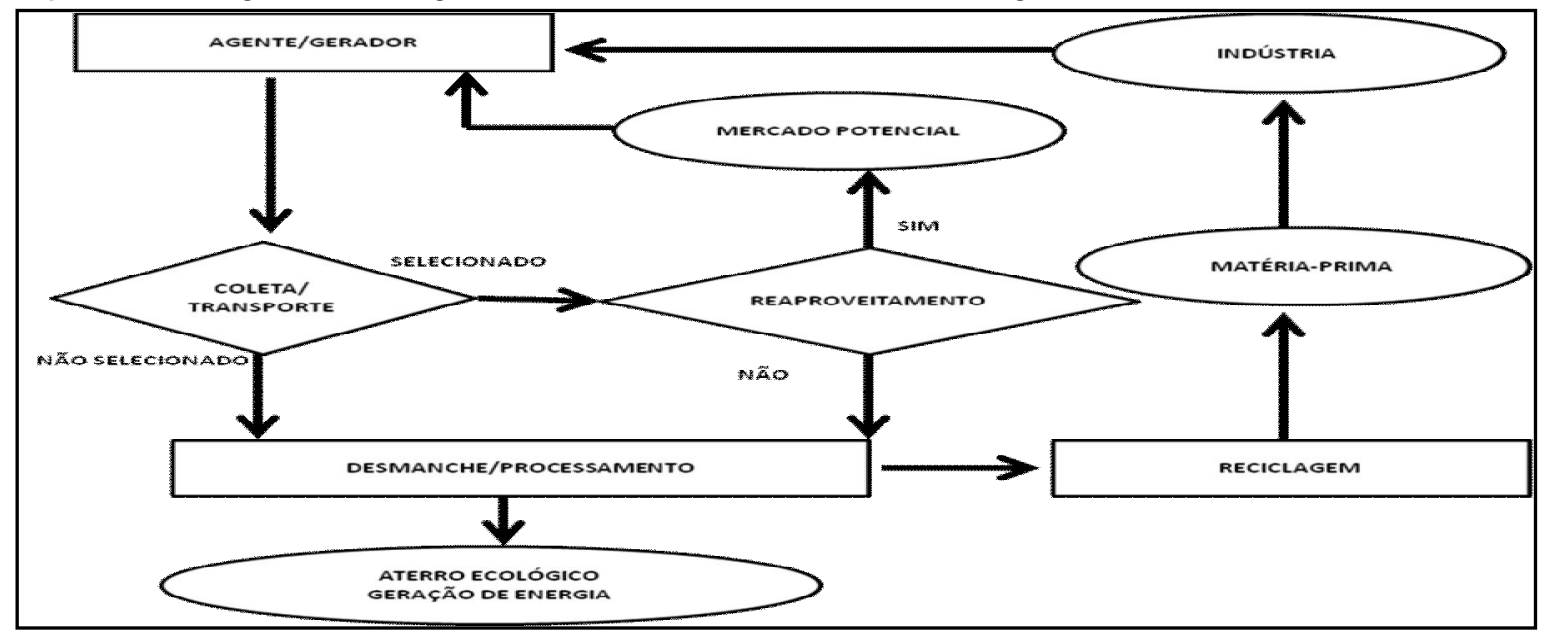

Fonte: Beiriz, 2005.

Analisando o ciclo de vida útil do EEE constata-se que cada vez mais são encurtados o tempo de uso, sendo esses rapidamente substituídos por novos modelos para poder atender às demandas da sociedade mundial. Tem-se como consequência uma maior geração de resíduos por parte do mercado. Gera-se um consenso para lidar com o problema de lixo tecnológico, adotando processos de logística reversa. A seguir será apresentado um conjunto de estratégias de gestão de destino do lixo eletrônico: 


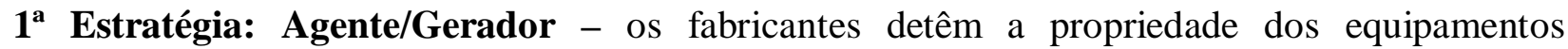
eletrônicos e ao término da vida útil estes retornam às fábricas nas quais seus componentes são reaproveitados ou reciclados, em projetos pré-concebidos para tal procedimento, dentro de uma política industrial. Atende-se a isto a necessidade de uma política voltada para o desenvolvimento de uma tecnologia de vida útil prolongada e ecológica, com uso de fontes de alimentação de maior autonomia.

$2^{\text {a }}$ Estratégia: Coleta/Transporte - com a obsolescência os equipamentos começam a convergir para o desmanche/remanufatura. O consumo dos EEE se dá de maneira a construir um cenário de grande dispersão dos insumos. Nessa estratégia tem-se uma política de logística reversa que envolve a sociedade com conscientização e incentivos, os fabricantes ou importadores com a responsabilidade sobre o tratamento do lixo tecnológico, inclusive transporte e armazenagem, e o governo evoluindo junto com as mudanças com a legislação e incentivos em prol do crescimento do mercado.

$3^{\text {a }}$ Estratégia: Reaproveitamento - nos Centros de Coleta, é proporcionada a convergência da segunda estratégia, onde é viabilizado o tratamento da terceira estratégia, o reaproveitamento, para atendimento de demanda de menor poder aquisitivo e inclusão da tecnologia.

Com o processo de reaproveitamento pode-se recondicionar os EEE obsoletos de forma a recolocá-los no mercado. O aproveitamento de componentes é o principal foco na utilização de partes que compõe um equipamento, por sua difícil utilização, seja econômica ou técnica.

Após o tratamento, o que for reutilizável segue para realimentar o mercado, sobre a forma de peças e componentes para manutenção. Para viabilizar a inclusão digital a um custo acessível, passa a ser fundamental a preocupação em direcionar as remanufaturas.

4 Estratégia: Desmanche/Processamento de Insumos - ao receber os insumos, ocorre o desmanche para melhor identificação das partes dos equipamentos, logo depois separados segundo o interesse de reciclagem, seguindo para a fase de trituração, sendo quebrados em pequenos pedaços e depois moídos.

Os resíduos não aptos à reciclagem, ou seja, os tóxicos são compactados e encapsulados para impedir o seu contato com o ecossistema é armazenado em aterros ecológicos. Tem-se um controle de entrada de resíduos industriais autorizados e compatíveis com as suas instalações e licenciamento ambiental do mesmo.

$5^{\mathbf{a}}$ Estratégia: Reciclagem - nesta estratégia pretende-se reciclar, ou seja, objetiva-se reaver insumos em escassez na natureza, tendo em vista os custos destes insumos encontrados na natureza e sua reserva, e visando ainda processos sustentáveis, reduzindo o impacto na geração do lixo tecnológico. $\mathrm{Na}$ atualidade, os processos requerem aprimoramento em escalas industriais e menor consumo de energia, sendo classificados em metalúrgicos, hidrometalúrgicos e pirometalúrgicos.

\section{A IMPLANTAÇÃO DE UM ECOPONTO NA UNIGRANRIO}

A ideia de implantação de um Ecoponto para a coleta de materiais eletrônicos microcomputadores e celulares - em um campus universitário da Universidade Unigranrio, no município de Magé, RJ, surgiu a partir da construção do trabalho de conclusão de curso. 
O Ecoponto em questão consiste num espaço com containers individualizados para o recolhimento de computadores e celulares. O projeto visa contribuir para a conscientização da população mageense, ensinando-os que o lixo tecnológico não deve ser jogado na rua entre outros locais, mas sim numa estação de tratamento adequado.

\section{METODOLOGIA}

Para esta pesquisa, os objetivos são classificados como conceitual, qualitativa, exploratória e bibliográfica. Sua característica conceitual é demonstrada quando obtém-se respostas às questões formuladas. É uma pesquisa exploratória, na medida em que, tem por objetivo verificar em que medida a obra consultada interessa à pesquisa (GIL, 2002).

Trata-se basicamente de uma pesquisa bibliográfica. Por se tratar de um estudo qualitativo, a identificação dos dados e informações foi adquirida a partir do estudo no contexto a ser desenvolvido, permitindo focalizar com maior precisão as questões a serem investigadas e formular mais as respostas (VERGARA, 1997).

A pesquisa de campo foi baseada no método Pesquisa-Ação, como cita Thiollent (1985) é um tipo de pesquisa social que é concebida e realizada em estreita associação entre os pesquisadores e os participantes.

\section{APRESENTAÇÃO DO PROCESSO DE PESQUISA}

A pesquisa de campo foi estruturada a partir dos seguintes passos, como ilustra a linha do tempo na figura 2:

Figura 2: Linha do Tempo
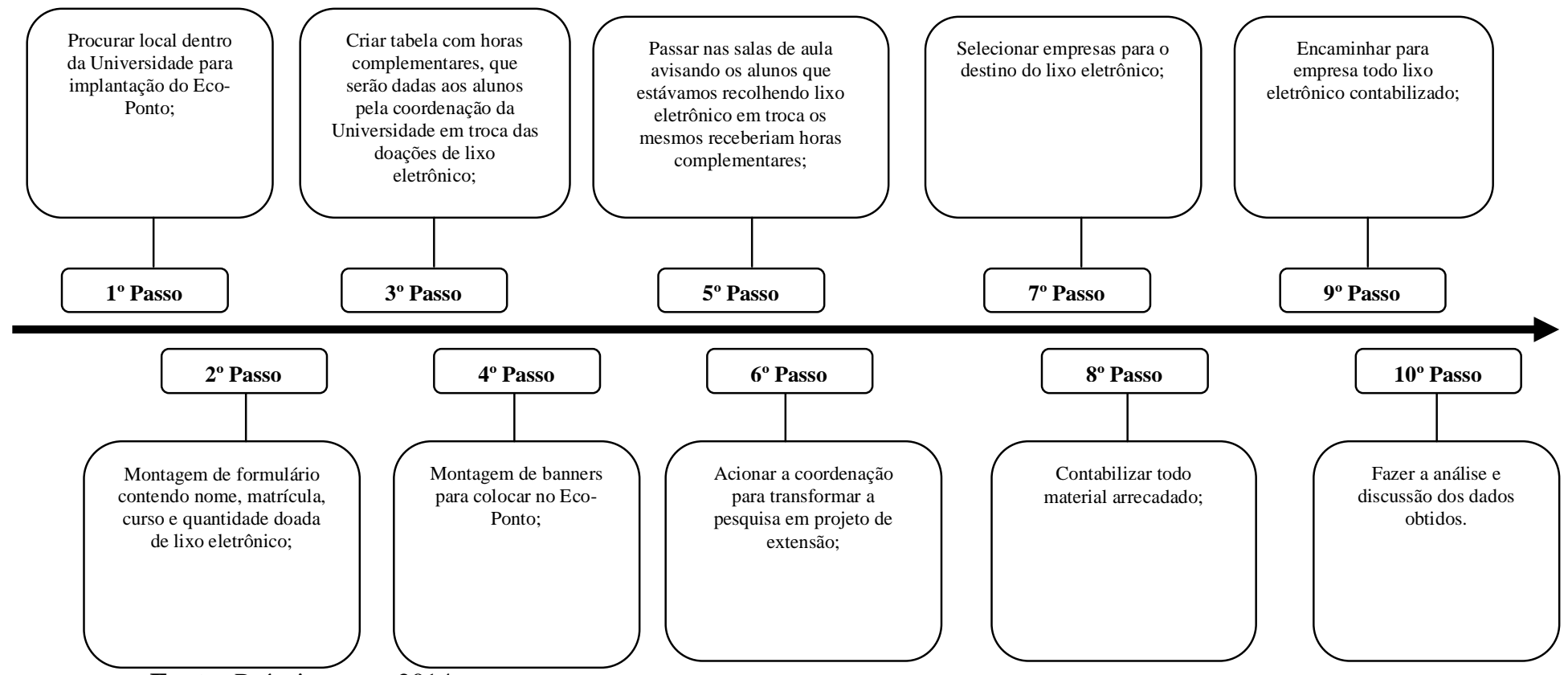

Fonte: Próprio autor, 2014. 


\section{ANÁLISE E DISCUSSÃO DOS DADOS OBTIDOS}

Concluídos todos os passos estabelecidos para a pesquisa de campo, foram transcritas todas as informações obtidas, os dados coletados foram agrupados de modo a orientar a elaboração de tabelas, gráficos e análises que visam fornecer os subsídios necessários para atingir os objetivos deste estudo.

Para colocar em prática a implantação do Eco-Ponto que "são estações de entrega voluntária de inservíveis, ou seja, de descarte de lixo de maneira totalmente gratuita e legalizada", foi discutida a aplicação do método Pesquisa-Ação tendo coparticipação da Universidade na criação da estrutura do Eco-Ponto (THIOLLENT, 1985).

A localização do Eco-Ponto teria que ser um local onde todos passassem sempre todos os dias, de forma que não deixassem de ver, lembrar, perguntar e participar. Por isso, foi escolhido no pátio da Universidade.

Para iniciar a parte prática foi necessário pensar em como seria armazenado todos os dados obtidos. Desta forma, foram criados formulários para mostrar aos alunos a quantidade de horas complementares e formulário para preenchimento do material coletado, veja: quadro $3,4 \mathrm{e}$ tabela 1.

Quadro 3: Formulário para Cadastrar as Doações de Lixo Eletrônico dos Alunos

\section{Formulário de Doações de Lixo Eletrônico}

\begin{tabular}{|c|c|c|c|c|c|c|c|c|c|c|}
\hline \multicolumn{6}{|c|}{ Nome do Aluno: } & \multicolumn{3}{|l|}{ Curso: } & \multicolumn{2}{|c|}{ Matrícula: } \\
\hline $\mathrm{CPU}$ & Celular & Smartphone & Notebook & Monitor & Mouse & Teclado & Placa-mãe & Baterias & Memória & Processador \\
\hline & & & & & & & & & & \\
\hline
\end{tabular}

Fonte: Elaboração Própria, 2014.

Quadro 4: Exemplo de Formulário de Doações Preenchido

\section{Formulário de Doações de Lixo Eletrônico}

\begin{tabular}{|c|c|c|c|c|c|c|c|c|c|c|}
\hline \multicolumn{6}{|c|}{ Nome do Aluno: } & \multicolumn{3}{|l|}{ Curso: } & \multicolumn{2}{|c|}{ Matrícula: } \\
\hline $\mathrm{CPU}$ & Celular & \begin{tabular}{|l|} 
Smartphone \\
\end{tabular} & Notebook & Monitor & Mouse & Teclado & Placa-mãe & Baterias & Memória & Processador \\
\hline & 1 & & & 1 & 5 & & & 3 & & \\
\hline
\end{tabular}

Fonte: Elaboração Própria, 2014.

Tabela 1: Horas Complementares

Tabela de Horas Complementares

\begin{tabular}{|l|l|}
\hline CPU e Notebook & 15 horas complementares \\
\hline Celular e Smartphone & 10 horas complementares \\
\hline Monitor, Mouse, Teclado, Placa-mãe, Memória, Processador e Baterias & 5 horas complementares \\
\hline
\end{tabular}

Foi criado também um banner para fazer a propaganda que para (KOTLER \& KELLER, 2006) "é uma tarefa específica de comunicação e um nível de sucesso a ser atingido em meio a determinado público, em um prazo estabelecido". Conforme figura 3.

A empresa que nos ajudou, recolhendo todo o lixo coletado, tem sua Razão Social como: Perterson Reciclagem em Geral. Essa empresa recebe os compostos eletrônicos e envia para outras empresas que trabalham com partes de computadores e celulares. 
Figura 3: Banner Eco-Ponto.

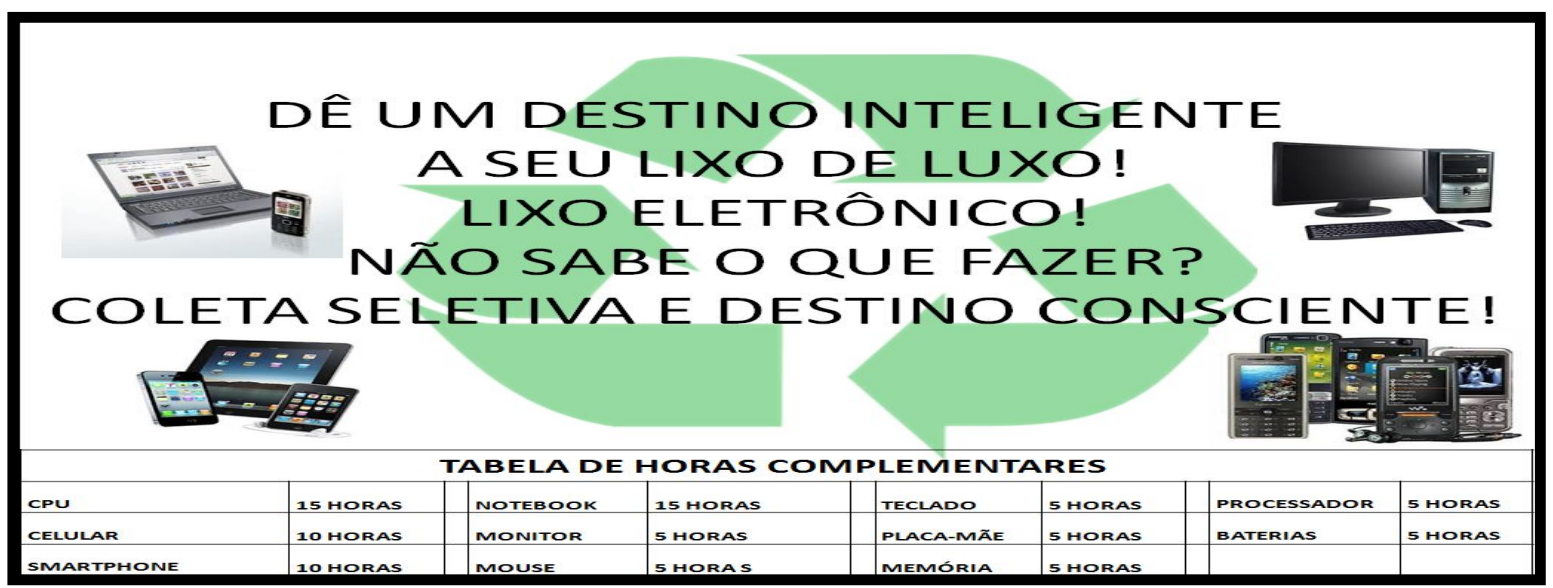

Fonte: Elaboração Própria, 2014.

Antes de enviar todo o material para a empresa escolhida, foi feita a contagem de todo material arrecadado, como é demonstrado na tabela 2 e no gráfico 1 a seguir.

Tabela 2: Total do Material Coletado

\begin{tabular}{|l|c|}
\hline \multicolumn{2}{|c|}{ TOTAIS } \\
\hline ITENS & UNIDADES \\
\hline CPU & 24 \\
\hline Notebook & 5 \\
\hline Celular & 755 \\
\hline Smartphone & 204 \\
\hline Monitor & 38 \\
\hline Mouse & 153 \\
\hline Teclado & 135 \\
\hline Placa-mãe & 77 \\
\hline Memória & 170 \\
\hline Processador & 63 \\
\hline Baterias & 1064 \\
\hline Pora & \\
\hline
\end{tabular}

Fonte: Elaboração Própria, 2014.

Gráfico 1: Total do Material Coletado

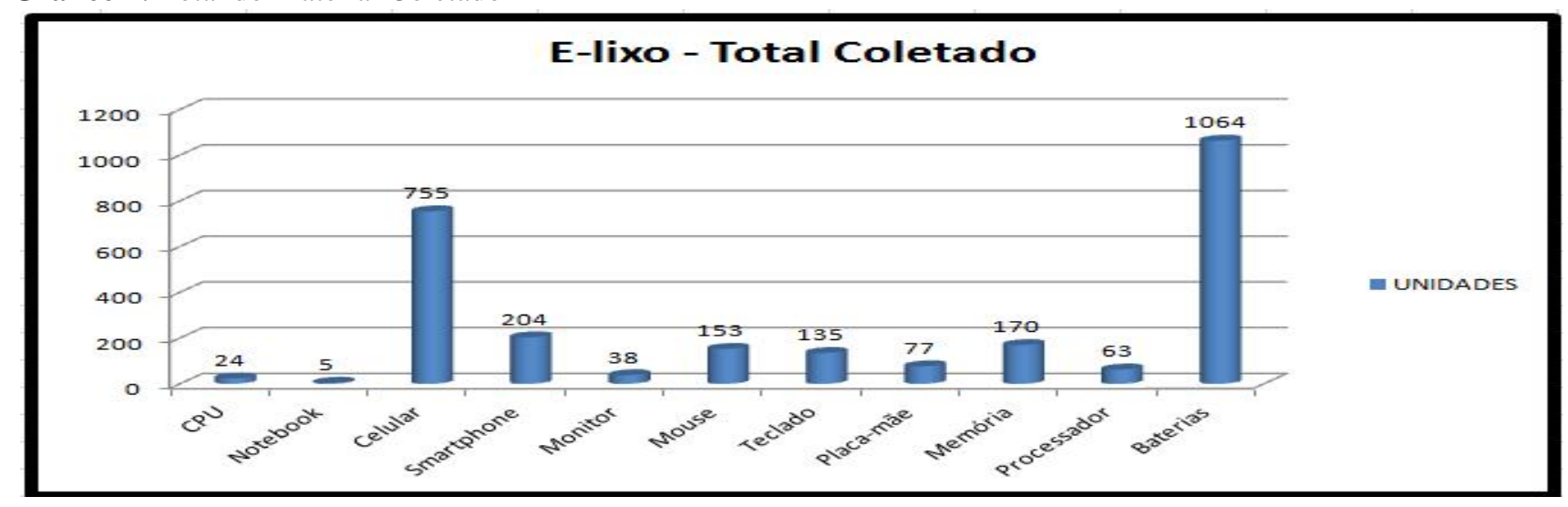

Fonte: Elaboração Própria, 2014. 
O recolhimento do material eletrônico foi feito por todos os componentes do grupo. Cada dia da semana ficou uma dupla envolvida na arrecadação de material. A contagem foi feita por todos os componentes.

Esse projeto foi uma experiência muito importante em nossas vidas, pois tivemos a chance de constatar que toda a parte teórica se transformou em realidade. E que tudo que foi dito e pesquisado para o artigo é uma verdade que todos vivemos, resultado da metodologia de Pesquisa-Ação (THIOLLENT, 1985).

A sociedade tem descartado seus equipamentos eletrônicos com muita facilidade em locais inadequados, e isso traz para o meio ambiente graves prejuízos, que só um processo de conscientização, de empresas e instituições comprometidas com o descarte ecologicamente correto do lixo eletrônico pode fazer toda a diferença.

\section{CONCLUSÃO}

O crescente interesse das organizações em introduzir a Logística Reversa em vários segmentos foi a motivação para tratar do tema do lixo tecnológico e seu significado e tendência na Era Digital, além das transformações que os dispositivos eletrônicos têm na vida diária de todos em uma sociedade.

O levantamento do problema de pesquisa estruturou os insumos tecnológicos mais utilizados e sua posição atual no mercado mundial, visando propiciar uma proposta de estratégia de gestão do lixo tecnológico.

Com a estratégia de gestão formulada, entende-se que deverá ser usada no sentido de resolver o descarte de lixo tecnológico de forma ecologicamente correta diminuindo e evitando a contaminação do meio ambiente com consequências positivas para o ser humano, viabilizando uma indústria lucrativa de reciclagem e aproveitamento de matéria-prima.

Portanto, é necessário o aperfeiçoamento quanto à legislação nacional atual, estabelecendo que os agentes responsáveis pelo recolhimento do lixo tecnológico, criem incentivos para o agente gerador, melhorando a rede de coleta, não existindo empecilhos legais no transporte do lixo tecnológico, definindo a estratégia, de forma que não ofereça riscos à sociedade.

A criação do Ecoponto incorporará na Universidade e na população mageense uma política de sensibilização a cerca da importância da adoção de procedimentos de controle e monitoração, criando-se uma cultura de preocupação no destino de produtos tecnológicos ao final de sua vida útil.

A todos envolvidos neste trabalho nosso agradecimento deixando claro que se cada um fizer a sua parte, teremos uma sociedade cada vez melhor!

\section{REFERÊNCIAS BIBLIOGRÁFICAS}

ARANTES, Nélio. Sistemas de gestão empresarial. São Paulo: Atlas, 1994.

BEIRIZ, Fernando Antônio Santos. Gestão Ecológica de Resíduos Eletrônicos. Dissertação (Mestrado em Sistemas de Gestão) - Universidade Federal Fluminense, Niterói, 2005.

BRASIL. Projeto de Lei $n^{\circ} 1991,2007$, art. $7^{\circ}$ inciso XII, p.3). 
CHIAVENATO, Idalberto. Introdução à teoria geral da administração. 6. ed. Rio de Janeiro: Campus, 2000.

FRANKE, Carsten. Tratamento de lixo tecnológico no Brasil e na União Europeia. Ambiente Brasil, São Paulo, 2004.

GIL, Antônio Carlos. Como elaborar projetos de pesquisa. 4. ed. São Paulo: Atlas, 2002, p. 18.

LEI FEDERAL 12.305/2010 - Artigo 33, incisos I, II, III, IV, V, VI.

KOTLER, Philip; KELlER, K. L. Administração de Marketing. 12. ed. São Paulo: Pearson Prentice Hall, 2006.

LEITE, P. R. (2003) Logística Reversa: meio ambiente e competitividade. São Paulo: Pearson Prentice Hall.

MANIFESTZINE. Lixo Eletrônico. Disponível em: http://manifestzine.blogspot.com.br. Acesso em: 01 de julho de 2010.

ONU - Organização das Nações Unidas. ONU e o Meio Ambiente, 2002.

SCHNEIDER, Vania Elizabeth. Manual de gerenciamento de resíduos sólidos em serviços de saúde. 2. ed. rev. e ampl. Caxias do Sul, RS: EDUCS, 2004.

THIOLLENT, M. (1997). Pesquisa-ação nas organizações. São Paulo: Atlas.

VERGARA, Sylvia Constante. Projetos e Relatórios de Pesquisa em Administração. 13ª ed. São Paulo: Atlas, 2011. 